\title{
Large chondral fragment of the lateral femoral condyle treated with arthroscopic internal fixation in an elite young athlete
}

\section{A case report}

\author{
Mitchell W. Beckert* and Robert G. Klitzman \\ Department of Orthopaedics, Indiana University, Indianapolis, IN, USA
}

Received 28 July 2019, Accepted 20 December 2019, Published online 8 January 2020

\begin{abstract}
Focal chondral lesions in the adolescent population create a particular challenge for orthopedic surgeons, and currently there exists no consensus on proper treatment. Numerous techniques for addressing focal chondral defects are employed in both pediatrics and adults, including fragment excision, debridement and fixation, bone marrow stimulation and microfracture techniques, cell-based options, as well as chondral and osteochondral grafts. Although historical evidence is mixed, recent reports of primary fixation of displaced cartilage fragments have shown favorable results. We present a case of reduction and fixation of a large displaced cartilage lesion in an elite young tennis player. Our results, in addition to other reports mentioned in this manuscript, highlight the importance of considering primary fixation of large chondral lesions when amenable to repair.
\end{abstract}

\section{Introduction}

Focal chondral lesions in the adolescent population create a particular challenge for orthopedic surgeons due to their limited healing potential [1]. Cartilage restoration techniques have seen significant advances in the last decade; however, their role in pediatric patients is not well-defined due to the lack of highquality, long-term data [2,3]. While displaced osteochondral lesions amenable to fixation have shown good outcomes [4-6], the success of fixation when cartilage fragments are devoid of subchondral bone is rarely described and previously been questioned [7]. The evidence for reduction and internal fixation of large cartilage fragments is limited to case reports [8-15], and the purpose of this study is to contribute yet another case to the literature of successful primary fixation of a large chondral fragment in the knee, here in a highly active young patient.

Both the patient and parents provided written informed consent to the submission of this case report.

\section{Case report}

An 11-year-old elite level male tennis player presented for evaluation of acute right knee pain after jumping and landing on his feet during a tennis tournament. The patient was

\footnotetext{
*Corresponding author: Mbeckert@iu. edu
}

accompanied to clinic by his father, who reported immediate pain, swelling, and locking of his knee after landing. He was unable to continue participation or bear weight on the affected leg. The patient denied any history consistent with patellar subluxation or dislocation. At the time the patient was the number two ranked tennis player in the United States for his age, and had traveled across the country to compete against players from all over the world. He was otherwise healthy and had no significant past medical, surgical, or relevant family history. He was a very active competitive athlete in the seventh grade.

The patient was first evaluated at an outside facility, where MRI demonstrated a large chondral defect sitting in the femoral notch. He subsequently was referred to a pediatric orthopedist who placed him in a knee immobilizer, recommended not to bear weight on the affected side, and referred the patient to see us in the orthopedic sports medicine clinic. The patient was 5 feet 1 inch tall, and weighed $44.6 \mathrm{~kg}$ at the time of examination. On physical exam, his right knee demonstrated a mild effusion. Range of motion testing was deferred to avoid further cartilage damage; however, the patient was comfortably resting at approximately $90^{\circ}$ of flexion and reported being able to bear weight on the right leg. He was neurovascularly intact. Examination of the contralateral knee was within normal limits, with range of motion negative $3-135^{\circ}$.

Radiographs obtained were normal without fracture or dislocation (Figures 1a and 1b). MRI demonstrated a $22 \times 20-\mathrm{mm}$ chondral defect originating from the lateral femoral condyle that was now sitting in the femoral notch (Figures $2 a$ and $2 b$ ). 
(a)

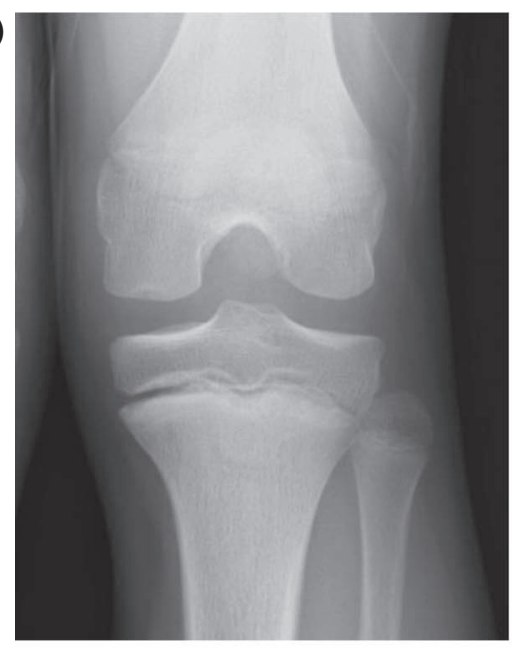

(b)

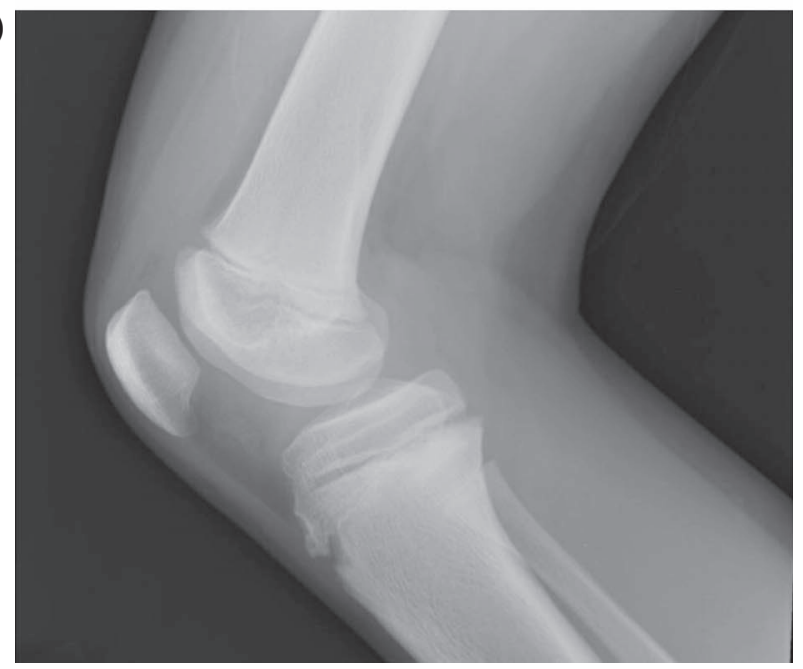

Figure 1. Preoperative AP and lateral radiographs unremarkable for bony pathology ( $a$ and $b$ ).

Likewise, the lateral femoral condyle showed a full thickness defect with no evidence of injury to the subchondral bone (Figure 3). There was no evidence of injury to the patellar cartilage or medial soft tissue restraints to suggest acute patellar dislocation. A lengthy discussion was had with the patient and father regarding the significance of this injury and need for surgical fixation to maximize both short and long term functional status of his knee. Consent for surgery was obtained and scheduled for 6 days after initial consultation. We stressed the importance of maintaining a non-weight bearing status to his right lower extremity in the interim to minimize risk of further damage to this loose cartilage fragment.

The patient was taken to surgery. An exam under anesthesia was then conducted. He was stable to varus and valgus stress and could achieve full extension. Flexion was not tested to protect his loose fragment within the knee. A diagnostic arthroscopy then took place. He was found to have no cartilage damage to the undersurface of the patella. No loose bodies were noted in the suprapatellar pouch, medial or lateral gutters. He had full-thickness cartilage loss of almost the entire upper lateral femoral condyle (Figures 4a and 4b). It did have full (a)

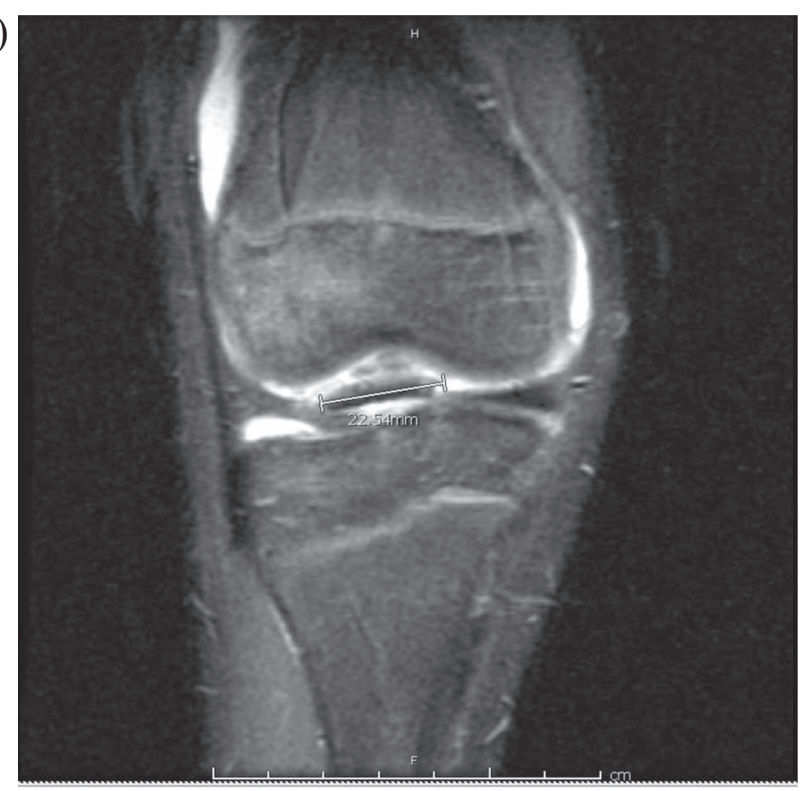

(b)

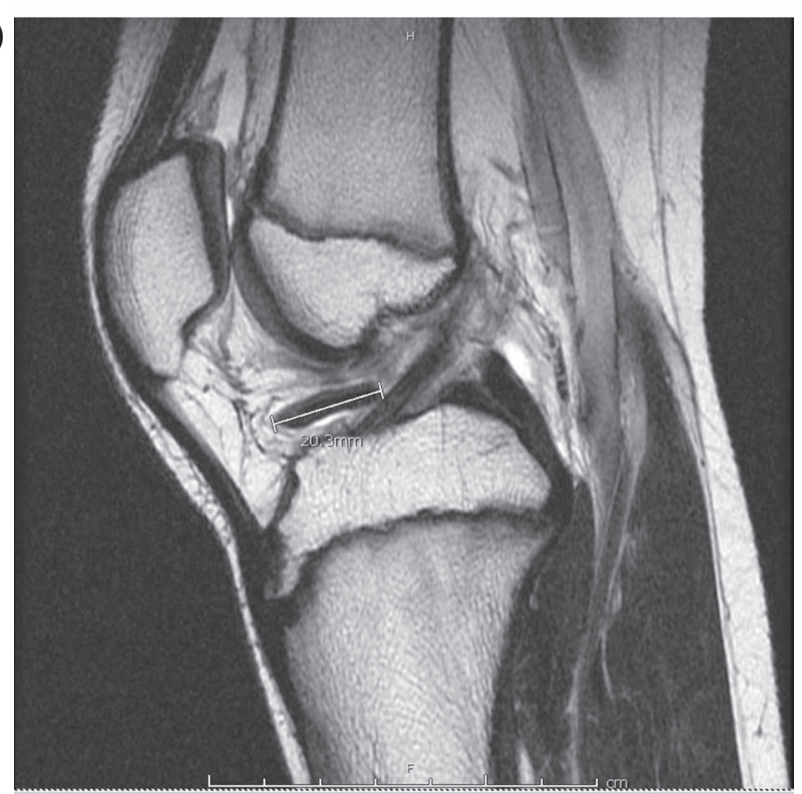

Figure 2. T2- and T1-weighted MRI demonstrating large chondral fragment within the intercondylar notch ( $\mathrm{a}$ and $\mathrm{b}$ ).

shoulders around the edges, where the cartilage was lost. It was greater than $2 \times 2 \mathrm{~cm}$. No cartilage damage was found to the rest of the lateral femoral condyle or the lateral tibial plateau. No cartilage damage to the medial femoral condyle or medial tibial plateau was appreciated. The medial and lateral menisci were intact without tears. Moving to the notch, the ACL and PCL were intact. The entire cartilage fragment was in one piece and sitting in the notch (Figures $5 \mathrm{a}$ and $5 \mathrm{~b}$ ). Next, curettes were used to scrape away the calcified layer over the exposed bone from the donor site of the cartilage on the lateral femoral condyle. The cartilage piece was then reduced and held in place with k-wires (Figure 6). Fixation was achieved with three absorbable Biotrak Helical Nails ${ }^{\odot}$ (Acumed, LLC, Hillsboro, Oregon, USA) in a triangular fashion to the underlying subchondral bone (Figure 7). The piece was then probed and 


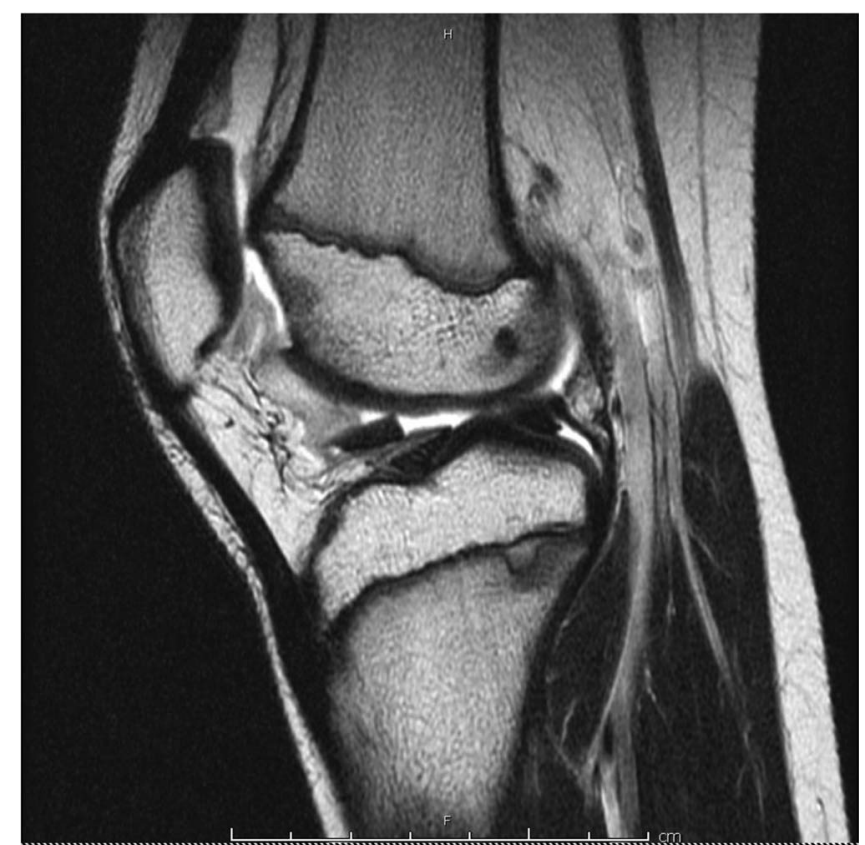

Figure 3. T1-weighted MRI showing full-thickness cartilage defect at the lateral femoral condyle.

(a)

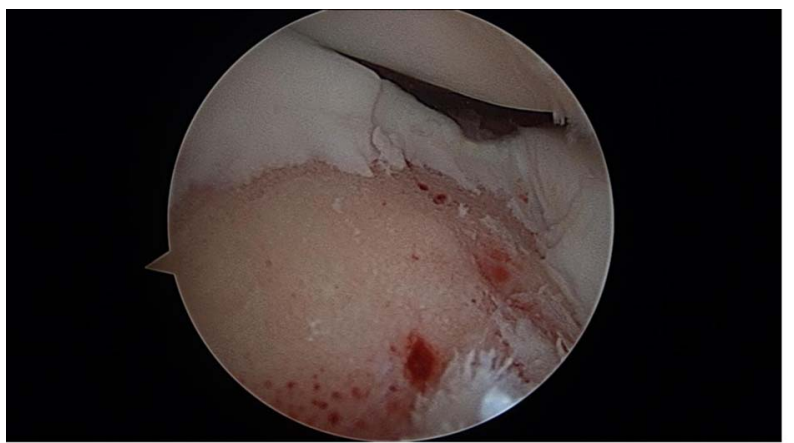

(b)

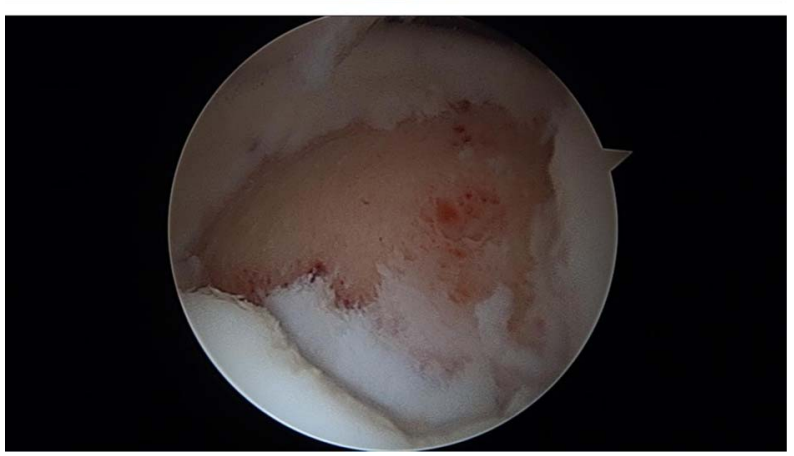

Figure 4. Intraoperative arthroscopic images showing large fullthickness cartilage defect at the lateral femoral condyle without disruption of the underlying subchondral bone ( $a$ and $b$ ).

found to be stable. Temporary fixation pins were removed, and the knee was ranged through a full arc of motion. The patella was observed to track well over the fixed piece. He was placed in a knee brace locked in extension immediately postoperatively. (a)

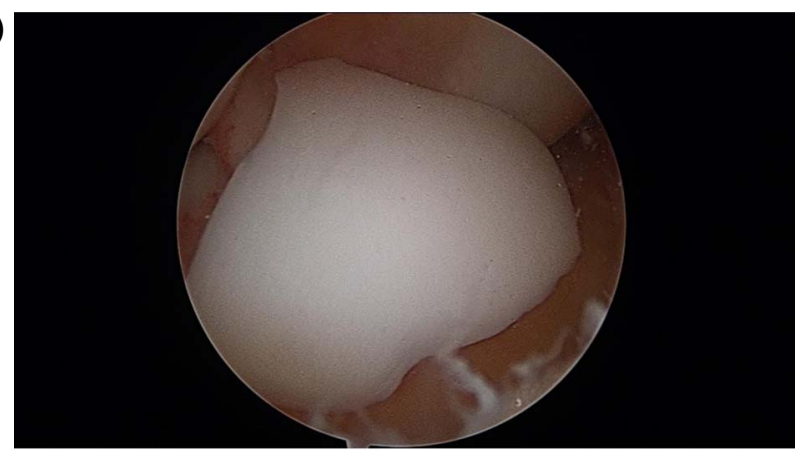

(b)

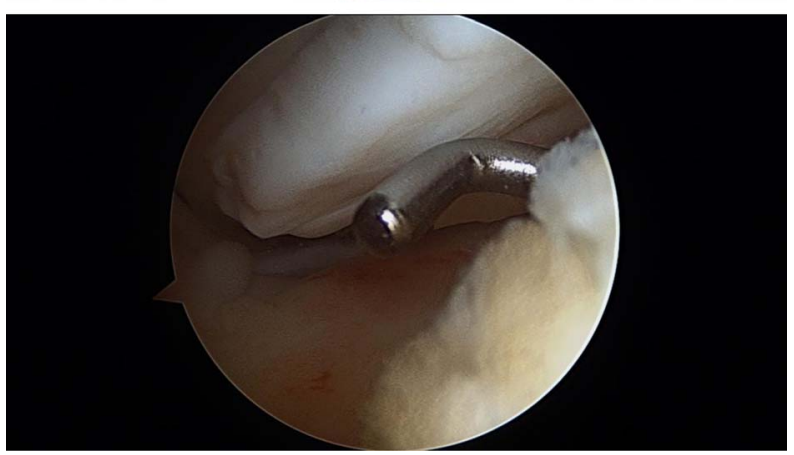

Figure 5. Intraoperative arthroscopic images showing the large loose chondral fragment. This was found in one large piece within the intercondylar notch, without underlying bony attachment ( $a$ and $b$ ).

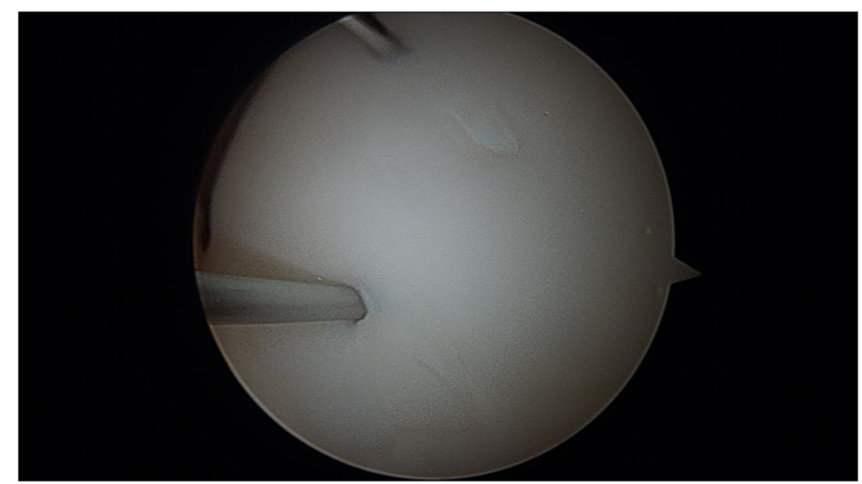

Figure 6. Provisional fixation of the chondral fragment using k-wires.

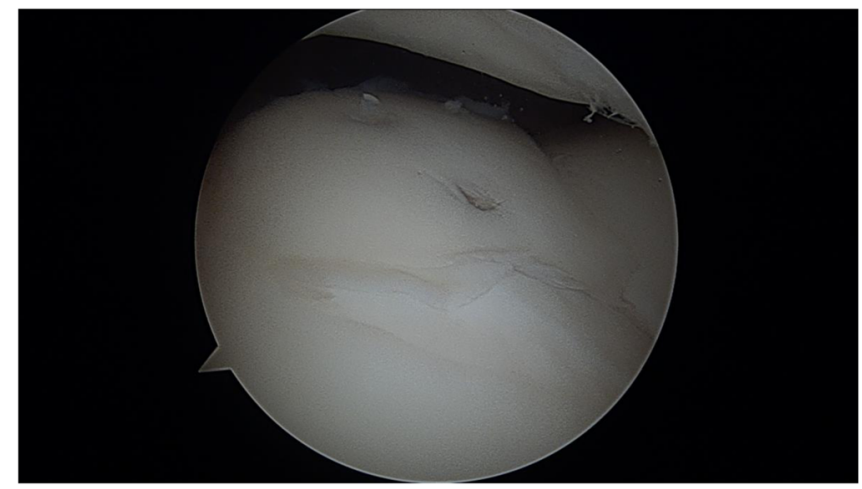

Figure 7. Definitive fixation of the chondral fragment using three bioabsorbable pins in a triangular fashion. 
(a)

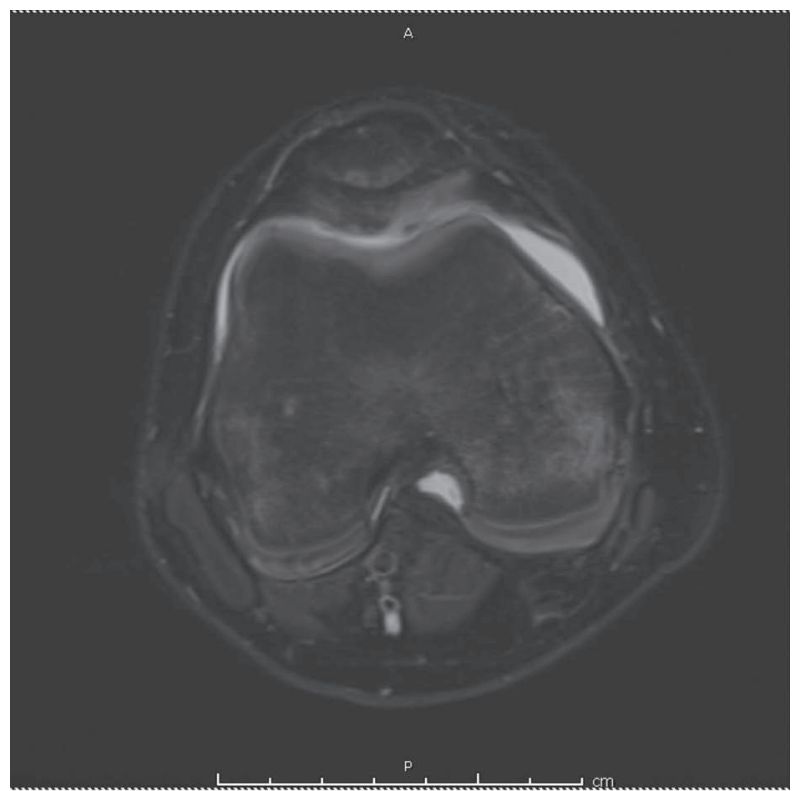

(b)

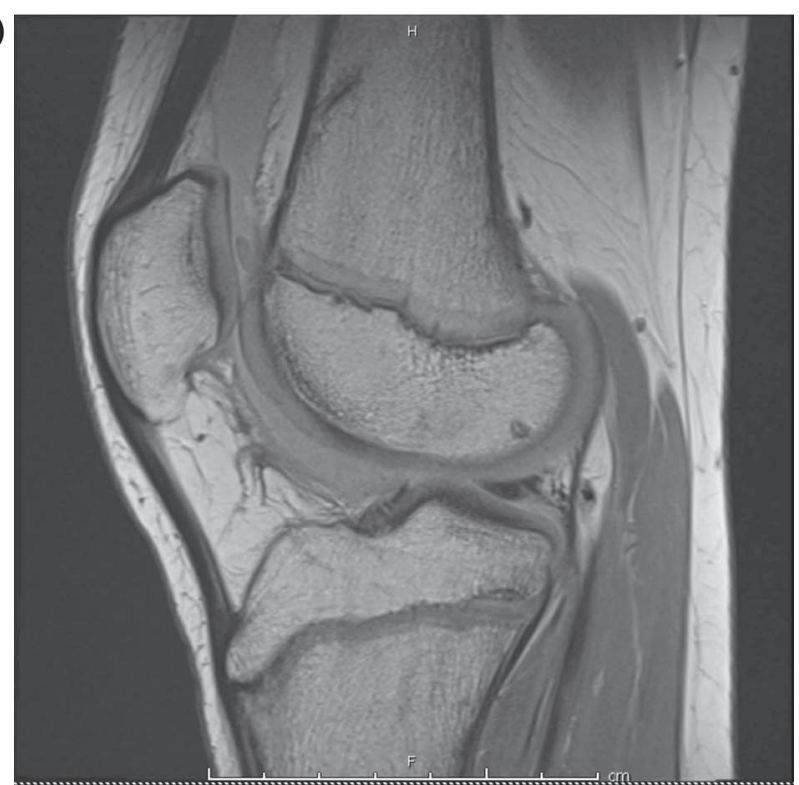

Figure 8. Axial T2- and sagittal proton density-weighted MRI showing incorporation of the previously fixed chondral fragment with near anatomic articular surface ( $a$ and $b$ ).

The patient was discharged from the hospital the same day with crutches and strict non-weight bearing status, using the brace during ambulation. The patient returned to clinic 2 weeks postoperatively where sutures were removed, and a continuous passive motion device was given to help improve his knee range of motion. He was given no restrictions to knee range of motion. At 6 weeks postoperatively the patient was allowed to begin bearing weight on his right leg with the brace locked in extension using crutches. Formal physical therapy was initiated at this time. At 8 weeks postoperatively the patient was allowed to walk with his brace unlocked with the assistance of crutches. At 10 weeks postoperatively he began walking in his brace without crutches. At 3 months postoperatively the patient (a)

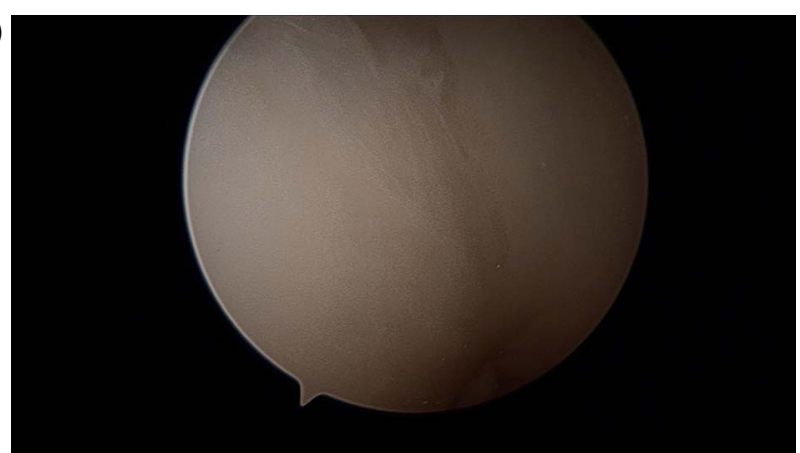

(b)

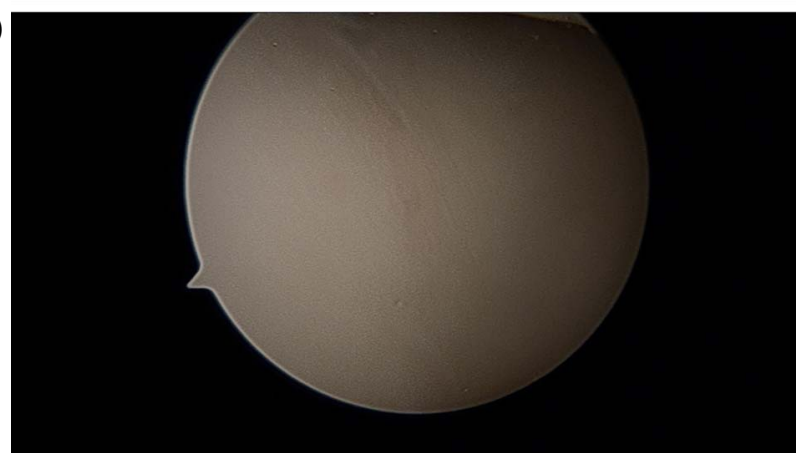

Figure 9. Second look arthroscopy showing excellent incorporation of the previously fixed chondral fragment with minimal articular cartilage irregularities ( $a$ and $b$ ).

reported beginning to hit tennis balls with his feet flat on the ground without pivoting on his right leg. At 4 months postoperatively the patient had weaned out of his brace and continued to hit tennis balls from a stationary position. He was allowed to slowly increase his activities at this time starting with a light jog and subsequently cleared to return to full activities at 6 months postoperatively.

By 7 months postoperatively the patient had played in two tennis tournaments, winning the second tournament. The patient was seen again 10 months out from his surgery and had recently returned from playing a clay court tournament in France. His right knee range of motion was $-3^{\circ}$ to $140^{\circ}$ and symmetric to the contralateral side. He had full quadriceps and hamstrings strength and complained of no pain or swelling. The patient returned to competitive sports; however, several months later he began complaining of some posterior right knee pain as well as intermittent swelling. MRI was obtained, now a year and a half out from the initial surgery, which showed a posterior medial meniscus tear with maintained reduction and apparent incorporation of the previously fixed chondral fragment (Figures $8 \mathrm{a}$ and $8 \mathrm{~b}$ ). He subsequently underwent repeat right knee arthroscopy and medial meniscus repair. At the time of arthroscopy (1 year, 9 months from the index procedure), the site of chondral fixation was found to have excellent incorporation with a nearly anatomic articular surface (Figures 9a and 9b). He rehabbed appropriately and recovered well from this injury. At final follow-up (2 years, 7 months) the patient had no pain, ranked in the top five nationally for his age, and continued to compete at an international level. 


\section{Discussion}

Osteochondral injuries in the pediatric population are welldocumented and most commonly caused by trauma, often following acute patellar dislocation, or a result of osteochondritis dissecans (OCD) [16-22]. Although osteochondral lesions usually have some degree of subchondral bone attachment, a cartilage fragment can occur in isolation. Previous biomechanical studies have shown decreased resistance to shear stress at the osteochondral junction in adolescents compared to adults, making adolescents more susceptible to this type of injury $[23,24]$. When a displaced fragment is purely cartilaginous, it creates a difficult dilemma for the treating physician with no clear consensus option. Various treatment options for chondral defects include fragment excision, debridement and fixation, bone marrow stimulation and microfracture techniques, cell-based options, as well as chondral and osteochondral grafts [2]. Goals of treatment are focused on restoring articular congruity of the joint surface and preventing future osteoarthritis [2, 21, 22].

Fixation has historically been indicated for the classic osteochondral defect with a true osseous component, while excision with or without restorative procedures reserved for the cartilage-only fragment $[25,26]$. Several authors have considered these cartilage fragments "unsalvageable" and routinely excise during surgery and are discarded [8, 25, 27-33]. Maletius and Lundberg reported poor healing potential in two cases of chondral fragment fixation, subsequently questioning the efficacy of this technique [7]. Recent reports, however, have shown successful fixation of purely cartilaginous lesions [8-15]. All cases were performed with open arthrotomies, except one case of a 22-year-old patient who underwent fixation of a $1.5 \mathrm{~cm}^{2}$ cartilage fragment with arthroscopy [15]. Previously described methods of fixation of these cartilage fragments include bone pegs, chondral darts, bioabsorbable nails, and headless screws, of which can be augmented by fibrin glue or suture [8-15].

Here we contribute another case of a large displaced osteochondral lesion completely devoid of bone that was successfully treated by native fragment reduction and fixation. Additionally, to our knowledge, this is the only case of successful fixation of a chondral-only fragment of this size by arthroscopic means.

\section{Conclusion}

Large displaced cartilage fragments in the pediatric knee without attachment of subchondral bone create a difficult problem for the orthopedic surgeon and patient. This case and other case reports previously mentioned highlight the importance of considering primary fixation as a treatment option for adolescents with this specific injury pattern. For young patients, the senior author (RGK) recommends arthroscopic reduction and fixation of displaced chondral and osteochondral lesions that are amenable to fixation to restore the native articular congruity.

\section{Conflicts of interest}

The authors have no conflicts of interest to report.

\section{References}

1. Sophia Fox AJ, Bedi A, Rodeo SA (2009) The Basic Science of Articular Cartilage: Structure, Composition, and Function. Sports Health 1, 461-468.

2. Moran CJ, Pascual-Garrido C, Chubinskaya S, et al. (2014) Restoration of articular cartilage. J Bone Joint Surg Am 96, 336-344.

3. Magnussen RA, Dunn WR, Carey JL, Spindler KP (2008) Treatment of focal articular cartilage defects in the knee: A systematic review. Clin Orthop Relat Res 466, 952-962.

4. Dines JS, Fealy S, Hollis PG, Warren RF (2008) Outcomes of osteochondral lesions of the knee repaired with a bioabsorbable device. Arthroscopy, 24, 62-68.

5. Chotel F, Knorr G, Simian E, Dubrana F, Versier G, French Arthroscopy Society (2011) Knee osteochondral fractures in skeletally immature patients: French multicenter study. Orthop Traumatol Surg Res 97, S154-S159.

6. Walsh SJ, Boyle MJ, Morganti V (2008) Large osteochondral fractures of the lateral femoral condyle in the adolescent: Outcome of bioabsorbable pin fixation. J Bone Joint Surg Am 90, 1473-1478.

7. Maletius W, Lundberg M (1994) Refixation of large chondral fragments on the weight-bearing area of the knee joint: A report of two cases. Arthroscopy, 10, 630-633.

8. Siparsky PN, Bailey JR, Dale KM, et al. (2017) Open reduction internal fixation of isolated chondral fragments without osseous attachment in the knee. Ortho J Sports Med 5, 1-8.

9. Song KW, Min BW, Bae KC, et al. (2015) Chondral fracture of the lateral femoral condyle in children with different treatment methods. J Pediatr Orthop B 25, 43-47.

10. Chan MC, King JJ, Farmer KW (2014) Fixation of chondral fracture of the weight-bearing area of the lateral femoral condyle in an adolescent. Knee Surg Sports Traumatol Arthrosc 22, 1284-1287.

11. Morris JK, Weber AE, Morris MS (2016) Adolescent femoral chondral fragment fixation with poly-L-lactic acid chondral darts. Orthopedics 39, e362-e366.

12. Nakamura N, Horibe S, Iwahashi T, et al. (2004) Healing of a chondral fragment of the knee in an adolescent after internal fixation. A case report. J Bone Joint Surg Am, 86, 2741-2746.

13. Nakayama H, Yoshiya S (2014) Bone peg fixation of a large chondral fragment in the weight-bearing portion of the lateral femoral condyle in an adolescent after internal fixation. A case report. J Med Case Rep 8, 316.

14. Uchida R, Toritsuka Y, Yoneda K, et al. (2012) Chondral fragment of the lateral femoral trochlea of the knee in adolescents. Knee 19, 719-723.

15. Anderson CN, Magnussen RA, Block JJ, et al. (2013) Operative fixation of chondral loose bodies in osteochondritis dissecans in the knee: A report of 5 cases. Orthop J Sports Med 1, eCollection.

16. Seeley MA, Knesek M, Vanderhave KL (2013) Osteochondral injury after acute patellar dislocation in children and adolescents. J Pediatr Orthop 33, 511-518.

17. Kramer DE, Pace JL (2012) Acute traumatic and sports-related osteochondral injury of the pediatric knee. Orthop Clin North Am 43, 227-236.

18. Duthon VB (2015) Acute traumatic patellar dislocation. Orthop Traumatol Surg Res 101, S59-S67.

19. Ries Z, Bollier M (2015) Patellofemoral instability in active adolescents. J Knee Surg 28, 265-277. 
20. Nomura E, Inoue M, Kurimura M (2003) Chondral and osteochondral injuries associated with acute patellar dislocation. Arthroscopy 19, 717-721.

21. Giacomo Z, Giovanni D, Matteo M (2014) Osteochondritis dissecans of the knee. Joints 2, 29-36.

22. Accadbled F, Vial J, Sales de Gauzy J (2018) Osteochondritis dissecans of the knee. Orthop Traumatol Surg Res 104, S97-S105.

23. Broom ND, Oloyede A, Flachsmann R, Hows M (1996) Dynamic fracture characteristics of the osteochondral junction undergoing shear deformation. Med Eng Phys 18, 396-404.

24. Flachsmann R, Broom ND, Hardy AE, Moltschaniwskyj G (2000) Why is the adolescent joint particularly susceptible to osteochondral shear fracture? Clin Orthop Relat Res 381, 212-221.

25. Hopkinson WJ, Mitchell WA, Curl WW (1985) Chondral fractures of the knee: Cause for confusion. Am J Sports Med 13, 309-312.

26. Salzmann GM, Niemeyer P, Hochrein A, et al. (2018) Articular cartilage repair of the knee in children and adolescents. Orthop J Sports Med 6, 1-12.
27. Dory MA (1983) Chondral fracture of the anterior intercondylar groove of the femur. Clin Rheumatol 2, 175-177.

28. Milgram JW, Rogers LF, Miller JW (1978) Osteochondral fractures: Mechanisms of injury and fate of fragments. AJR: Am J Roentgenol 130, 651-658.

29. Ahstrom JP Jr (1965) Osteochondral fracture in the knee joint associated with hypermobility and dislocation of the patella. Report of eighteen cases. J Bone Joint Surg Am 47, 1491-1502.

30. Makin M (1951) Osteochondral fracture of the lateral femoral condyle. J Bone Joint Surg Am 33, 262-264.

31. Matthewson MH, Dandy DJ (1978) Osteochondral fractures of the lateral femoral condyle: A result of indirect violence to the knee. J Bone Joint Surg Br 60, 199-202.

32. Rorabeck CH, Bobechko WP (1976) Acute dislocation of the patella with osteochondral fracture: A review of eighteen cases. J Bone Joint Surg Br 58, 237-240.

33. Sledge SL (2001) Microfracture techniques in the treatment of osteochondral injuries. Clin Sports Med 20, 365-377.

Cite this article as: Beckert MW \& Klitzman RG (2020) Large chondral fragment of the lateral femoral condyle treated with arthroscopic internal fixation in an elite young athlete. SICOT-J 6, 1 